\title{
Role of Proprioception in Pathoetiology of Shoulder Instability
}

\author{
Jon J.P. Warner, MD*; Scott Lephart, PhD, ATC**; \\ and Freddie $\mathrm{H}$. Fu, $\mathrm{MD} \dagger$
}

\begin{abstract}
Proprioception is a specialized sensory modality that gives information about extremity position and direction of movement. This kind of afferent sensory feedback is probably important in mediating muscular control of the shoulder joint. As this articulation is minimally constrained, such a coordinated dynamic control of muscles about the joint is necessary for stability during arm motion. The authors evaluated proprioception in individuals with normal shoulders, unstable shoulders, and after surgical stabilization, by assessing threshold to detection of passive motion and the ability to passively reposition the arm in space. In normal shoulders there is no difference between the dominant and nondominant shoulder, though in unstable shoulders there is a significantly decreased proprioceptive ability. Surgical stabilization normalizes proprioception of the shoulder.
\end{abstract}

Because the human glenohumeral joint is minimally constrained by articular surface conformity, static and dynamic stability is provided by the combined effect of both capsuloligamentous structures and rotator cuff and biceps. $21.37 .40-42$ The ligamentous struc-

From the *Shoulder Service, **Athletic Trainer Program, and $\dagger$ Center for Sports Medicine, University of Pittsburgh, Pittsburgh, PA.

Reprint requests to Jon J.P. Warner, MD, 4601 Baum Boulevard, Pittsburgh, PA 15213. tures, however, function only at extreme positions of rotation to prevent excessive translation or rotation of the humeral head on the glenoid. In the midranges of rotation, the capsuloligamentous structures remain relatively lax. ${ }^{11.19,20,29.36 .38 .41}$ In the midranges of motion most joint stability is through dynamic action of the rotator cuff and biceps tendons. Contraction of these muscle tendon units creates joint compression and increases the concavity compression fit of the humeral head into the glenoid socket. 7.28 Furthermore, a coordinated, synergistic contraction of the rotator cuff and biceps may protect the ligamentous structures from injury by increasing torque resistance against excessive rotation and preventing excessive translations of the humeral head. $6.8 .9 .13 .14 .22,32 \mathrm{Be}$ cause the glenohumeral ligaments are relatively weak $^{4,31}$ compared with the knee ligaments, such a dynamic protective mechanism is important to prevent injury to these structures.

\section{HYPOTHESIS: THE ROLE OF PROPRIOCEPTION}

Placement of the hand for upper limb function is partially dependent on the perception of joint position and joint motion of the shoulder. This sensory modality is termed proprioception and is mediated by peripheral receptors in articular, muscular, and cutaneous 
structures. Specialized nerve endings, proprioceptive mechanoreceptors (Pacinian corpuscles, Ruffini endings, Golgi tendon organlike endings), have been shown in the capsule and ligaments of all joints. ${ }^{1-3.10,12,15-18,24,33,35,39}$ These mechanoreceptors are specialized neurons that transduce mechanical deformation into electrical signals that transmit information about joint position and motion. ${ }^{16.17}$ Stimulation of these receptors results in reflex muscle contraction about the joint as an adaptive control to sudden movements of acceleration or deceleration. ${ }^{3.35}$ It has been suggested that receptors in the joint capsule respond primarily to extreme ranges of motion, ${ }^{16.17}$ or deep pressure that may occur with translation of the humeral head on the glenoid. ${ }^{10.15-17}$

Proprioceptive sensibility encompasses the sensation of joint motion (kinesthesia) and joint position (joint position sense). Normal proprioceptive sensation and the effect of injury have been shown in the ankle ${ }^{12,24}$ and knee 1.2 .23 .26 .30 Furthermore, shoulder instability is associated with proprioceptive deficits. ${ }^{34}$ The hypothesis of the authors' studies is that the capsuloligamentous structures may contribute to stability by providing an afferent feedback for reflexive muscular contraction of the rotator cuff and biceps. This dynamic reflexive muscle action may protect against excessive translations and rotations of the glenohumeral joint. Blasier and coworkers 5 have proposed a similar mechanism. Moreover, the authors have hypothesized that injury to these ligaments will result in measurable deficits in proprioception.

\section{RECENT STUDIES}

For the past 5 years the authors have studied proprioception in normal, anteriorly unstable, and surgically reconstructed shoulders. ${ }^{25.27}$

\section{Testing Methods}

Using a specialized testing apparatus (Fig 1) threshold to detection of passive motion and reproduction of passive positioning was tested. The shoulder was positioned at $90^{\circ}$

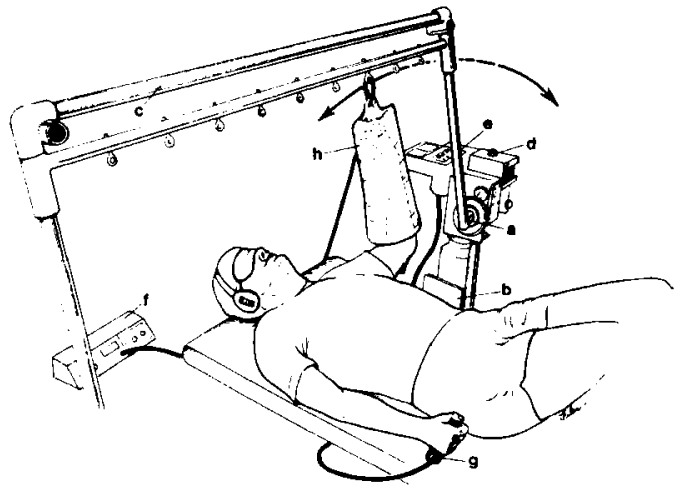

Fig 1. Proprioception testing device. (a) Rotational transducer (1:3 mechanical speed reduction gear train); (b) motor; (c) moving arm; (d) control panel; (e) digital microprocessor; (f) pneumatic compression device; $(\mathrm{g})$ handheld disengage switch; $h=$ pneumatic compression sleeve. Threshold to detection of passive motion is assessed by measuring angular displacement until the subject senses shoulder motion and presses the disengage switch $(\mathrm{g})$. (Reprinted with permission from Lephart SM, Warner JJP, Borsa PA, Fu FH: Proprioception of the shoulder joint in healthy, unstable, and surgically repaired shoulders. J Shoulder Elbow Surg 3:371-380, 1994).

abduction in the plane of the body with the elbow at $90^{\circ}$, and all external stimuli were eliminated by use of a pneumatic cuff applied to the arm, a blindfold, and white noise introduced through headphones. The shoulder was moved at a constant angular velocity of $0.5^{\circ}$ per second, with random movement into either internal or external rotation. The test subject indicated when motion was felt by turning off the machine with a button he or she held in the other hand. This tested TTDPM. The RPP was measured by asking the patient to reproduce the initial position in which the shoulder had been placed after it was moved from that reference point. Accuracy was measured as the error in degrees from the starting position.

\section{Results}

A total of 90 subjects were tested: 40 healthy college age individuals with normal shoulders; 30 patients with documented posttraumatic, 
anterior instability; and 20 patients who had either arthroscopic or open Bankart repairs. All subjects were comparable in gender and age. It was determined that the TTDPM in subjects with normal shoulders averaged 1.5 to $2.2^{\circ}$ for
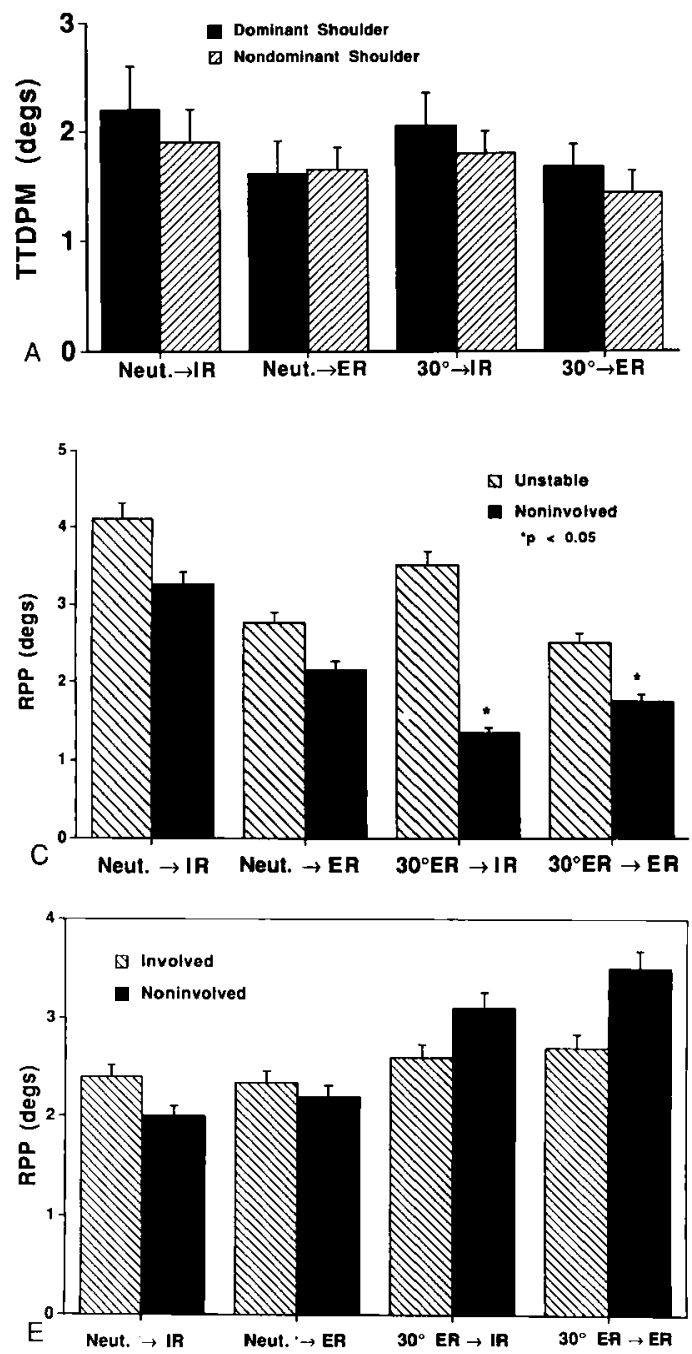

all testing conditions and there was no significance of hand dominance (Fig 2A). The subjects with unstable shoulders had a TTDPM value of approximately $2.8^{\circ}$ and this was significantly $(p<0.005)$ increased compared with

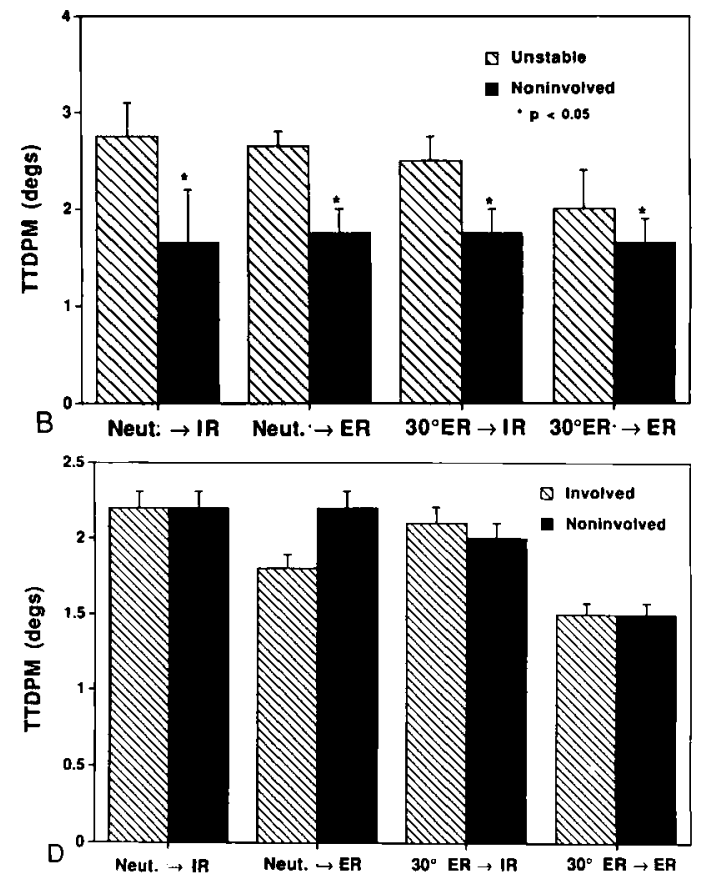

Fig 2A-E. (A) Results are means and standard error of the mean for TTDPM (degrees) of the dominant and nondominant shoulder from starting positions of neutral rotation and $30^{\circ}$ external rotation moving into both internal and external rotation. (B) Results are means and standard error of the mean for TTDPM (degrees) of unstable and uninvolved shoulder from starting positions of neutral rotation and $30^{\circ}$ external rotation moving into both internal and external rotation. (C) Results are means and standard error of the mean for RPP (degrees) for unstable and uninvolved shoulders from starting positions of neutral and $30^{\circ}$ external rotation moving into both internal and external rotation. (D) Results are means and standard error of th mean for TTDPM (degrees) in reconstructed and uninvolved shoulders from starting positions of neutral rotation and $30^{\circ}$ external rotation moving into both internal and external rotation. (E) Results are means and standard error of the mean for RPP (degrees) in reconstructed and uninvolved shoulders from staring positions of neutral rotation and $30^{\circ}$ external rotation moving into internal and external rotation. (Reprinted with permission. ${ }^{27}$ ) 
the shoulders in the subjects with normal shoulders (Fig 2B). RPP was also significantly $(p<0.01)$ less accurate by approximately $1^{\circ}$ in the unstable shoulders compared with the normal shoulders (Fig 2C). In patients whose shoulder instability had been repaired, the TTDPM and RPP were no different from that in patients with normal shoulders (Fig 2D).

\section{CONCLUSIONS}

It is concluded that there is an association of proprioceptive sensibility with shoulder instability, and surgery restores normal sensibility; however, the testing speed used in the present study was much slower than the speeds that occur with throwing or swimming. Therefore, it is difficult to extrapolate directly to the clinical situation. It is proposed that 1 mechanism for gradual development of shoulder instability may be cumulative injury to the capsuloligamentous structures with loss of this proprioceptive feedback mechanism and, thus, reflexive muscular protection against excessive humeral head translations and rotations.

Blasier and colleagues 5.6 have suggested that individuals with generalized ligamentous laxity have poorer proprioceptive abilities in their shoulders, though their numbers were small and their testing methods were somewhat different than those used here. Future studies will examine the effectiveness of proprioceptive training in nonoperative treatment of instability, and the affect of constitutional hyperlaxity on proprioceptive sensibility.

\section{References}

1. Barrack RL, Skinner HB, Buckley SL: Proprioception in the anterior cruciate ligament deficient knee. Am J Sports Med 17:1-6, 1989.

2. Barrack RL, Skinner HB, Brunet ME: Joint laxity and proprioception in the knee. Physiol Sports Med 11:130-135, 1983.

3. Barrett DS, Cobb AG, Bently G: Joint proprioception in normal, osteoarthritic and replaced knees. J Bone Joint Surg 13B:53-56, 1991.

4. Bigliani LU, Pollock RG, Soslowski LJ, et al: Tensile properties of the inferior glenohumeral ligament. J Orthop Res 10:187-197, 1992.

5. Blasier RB, Carpenter JE, Huston LJ: Shoulder proprioception. Effect of joint laxity, joint position, and direction of motion. Orthop Rev 23:45-50, 1994.

6. Blasier RB, Goldberg RE. Tothman ED: Anterior shoulder stability: Contributions of rotator cuff forces and capsular ligaments in a cadaver model. $\mathbf{J}$ Shoulder Elbow Surg 1:140-150, 1992.

7. Bowen MK, Deng X. Warner JJP, Warren RF: The elfect of joint compression on the stability of the glenohumeral joint. Trans Orthop Res Soc 17:289. 1992.

8. Bradley JP. Tibone JE: Electromyographic analysis of muscle action about the shoulder. Clin Sports Med 10:789-805, 1991.

9. Cain PR, Mutschler TA, Fu FH, Harner CD: Anterior stability of the glenohumeral joint: A dynamic model. Am J Sports Med 15:144-148, 1987.

10. Clark FJ, Burgess PR: Slowly adapting receptors in the cat knee joint: can they signal joint angle? J Neurophysiol 38: 1448-1463, 1975.

11. Emery RJ. Mullaji MB: Glenohumeral instability in normal adolescents. J Bone Joint Surg 73B:406-408. 1991.

12. Glencross D. Thornton E: Position sense following joint injury. J Sports Med 21:23-27, 1981

13. Glousman R, Jobe FW, Tibone JE. Perry J. Moynes DR: Dynamic electomyographic analysis of the throwing shoulder with instability. J Bone Joint Surg 70A:220-226, 1988.

14. Gowan JP, Jobe FW. Tibone JE, Perry J, Moynes DR: A complete electromyographic analysis of the shoulder during pitching. Am J Sports Med 15:586-590. 1987.

15. Grigg P: Responses of joint afferent neurons in cat medial articular nerve to active and passive movements of the knee. Brain Res 118:482-485, 1976.

16. Grigg P, Hoffman AH: Properties of Ruffini afferents revealed by stress analysis of isolated sections of cat knee capsule. J Neurophysiol 47:4I-54, 1982.

17. Grigg P, Hoffman AH: Calibrating joint capsule mechanoreceptor as in-vivo soft tissue load cells. J Biomech 22:781-785, 1989

18. Guyton AC: Textbook of Medical Physiology. 5 Philadelphia, WB Saunders 104-146, 1976.

19. Harryman III DT, Sidles JA, Clark JM, et al: Translation of the humeral head on the glenoid with passive glenohumeral motion. J Bone Joint Surg 72A:1334-1343, 1990.

20. Harryman III DT, Sidles JA, Harris SL, Matsen III FA: Laxity of the normal glenohumeral joint: A quantitative in-vivo assessment. J Shoulder Elbow Surg 1:66-76, 1992.

21. Itoi E. Kuechle DK. Newman SR, Morrey BF. An K-N: Stabilizing function of the biceps in stable and unstable shoulders. J Bone Joint Surg 75B:546-551, 1993.

22. Itoi E, Newman SR, Kuechle DK, Morrey BF, An K$\mathrm{N}$ : Dynamic anterior stabilizers of the shoulder with the arm in abduction. J Bone Joint Surg 76B: 834-836, 1994.

23. Kennedy JC, Alexander IJ, Hayes KC: Nerve supply of the human knee and its functional importance. Am J Sports Med 10:329-335, 1982.

24. Konradsen L, Raven JB: Ankle instability caused by prolonged peroneal reaction time. Acta Orthop Scand 61S:338-390, 1990. 
25. Lephart SM, Conners C, Fu FH, Irrgang JJ, Borsa PA: Proprioceptive characteristics of trained and untrained college females. Med Sci Sports Exerc 23:4, 1991.

26. Lephart SM, Kocher MS, Fu FH, Borsa PA, Harner CD: Proprioception following ACL reconstruction. J Sports Rehabil 1:188-196, 1992.

27. Lephart SM, Warner JJP, Borsa PA, Fu FH: Proprioception of the shoulder joint in normal, unstable, and surgically repaired individuals. J Shoulder Elbow Surg 3:371-379, 1994.

28. Lippitt SB, Vanderhooft E, Harris SL, et al: Glenohumeral stability from concavity-compression: A quantitative analysis. J Shoulder Elbow Surg 2:27-35, 1993.

29. O'Connell PW, Nuber GW, Mileski RA, Lautenschlager E: The contribution of the glenohumeral ligaments to anterior stability of the shoulder joint. Am J Sports Med 18:449-456, 1990.

30. Pope MH, Johnson RH, Brown DW: The role of musculature in injuries to the medial collateral ligament. J Bone Joint Surg 61 A:398-402, 1979.

31. Reeves B: Experiments on tensile strength of the anterior capsular structures of the shoulder in man. $J$ Bone Joint Surg 50B:858-865, 1968.

32. Rodosky MW, Harner CD, Fu FH: The role of the long head of the biceps muscle and superior glenoid labrum in anterior stability of the shoulder. Am J Sports Med 22:121-130, 1994.

33. Skoglund CT: Joint Receptors and Kinesthesia. Handbook of Sensory Physiology. Berlin, Springer 111-135, 1973.

34. Smith RL, Brunolli J: Shoulder kinesthesia after anterior glenohumeral dislocation. Phys Ther 69:106-112, 1989.
35. Sojka P, Sjolander P, Johansson H, Djupsjobacka $M$ : Influence from stretch sensitive receptors in the collateral ligament of the knee joint on the gamma-muscle spindle systems of flexor and extensor muscles. Neurosci Res 11:55-62, 1991 .

36. Terry GC, Hammon D, France P, Norwood L: The stabilizing function of passive shoulder restraints. Am J Sports Med 19:26-34, 1991.

37. Turkel SJ, Panio MW, Marshall JL, Girgis FG: Stabilizing mechanisms preventing anterior dislocation of the glenohumeral joint. J Bone Joint Surg 63A:1208-1217, 1981.

38. Uthoff $\mathrm{H}$, Piscopo $\mathrm{M}$ : Anterior capsular redundancy of the shoulder: Congenital or traumatic? J Bone Joint Surg 67B:363-365, 1985.

39. Vangsness CT, Ennis M: Neural anatomy of the human glenoid and shoulder ligaments. Annual Meeting of the American Academy of Orthopaedic Surgeons, Washington, DC 205, 1992.

40. Warner JJP: The Gross Anatomy of the Joint Surfaces, Ligaments, Labrum, and Capsule. In Matsen III FA, Fu FH, Hawkins RJ (eds). The Shoulder: A Balance of Mobility and Stability. Rosemont, IL, AAOS 7-27, 1993.

41. Warner JJP, Caborn DNM, Berger R, Fu FH, Seel M: Dynamic capsuloligamentous anatomy of the glenohumeral joint. J Shoulder Elbow Surg 2:115-133, 1993.

42. Warner JJP, Deng X, Warren RF, Torzilli PA: Static capsuloligamentous restraints to superior-inferior translation of the glenohumeral joint. Am J Sports Med 20:675-685, 1992. 